\title{
Relation between Personality and Ventilatory Response to Carbon Dioxide in Normal Subjects: A Role in Asthma?
}

\author{
N. A. SAUNDERS, SANDRA HEILPERN, A. S. REBUCK
}

British Medical fournal, 1972, 1, 719-721

\section{Summary}

Ventilatory response to carbon dioxide, as an index of respiratory centre sensitivity, was measured in $\mathbf{5 0}$ normal subjects. Their personality was documented in terms of extraversion and neuroticism scores by the Eysenck Personality Inventory. A significant correlation was found between extraversion score and ventilatory response to carbon dioxide in women $(P<0.005)$ but not in men. No correlation was found between ventilatory responsiveness and neuroticism score in either sex. It is suggested that the degree of extraversion may play some part in determining the level of ventilation adopted, and hence of arterial carbon dioxide tension, if and when women develop lung disease such as asthma.

\section{Introduction}

Studies of sensitivity of the central respiratory neurones in normal subjects by measuring changes in pulmonary ventilation in response to high levels of inspired carbon dioxide are becoming established in clinical investigation. Read's (1967) rebreathing method for assessing ventilatory response to carbon dioxide is well suited to clinical research. The results obtained are similar to those obtained by the older and more prolonged steady-state methods, both in normal subjects and in patients with lung disease (Clark, 1968).

The reported range of ventilatory response to carbon dioxide in subjects free from lung disease extends from 0.57 to 8.17 litres $/ \mathrm{min} / \mathrm{mm} \mathrm{Hg}$ (Rebuck and Read, 1971), but for any one subject the response is highly reproducible on repeated testing (Read, 1967). However, no reports of correlation between ventilatory response to carbon dioxide and age, sex, body size, or other measures of respiratory function in normal subjects have been noted.

A relation between extraversion and mixed venous carbon dioxide tension has been shown in patients with chronic obstructive airways disease (Clark and Cochrane, 1970). These workers suggested that this might have been due to increased central chemoreceptor excitability in extraverted patients. Comparable information in normal subjects would be helpful to show whether this was a primary or secondary phenomenon.

The present study investigates the hypothesis that a relation exists between ventilatory response to carbon dioxide and personality in subjects free from lung disease. The results indicate a relation between extraversion and central chemoreceptor sensitivity in healthy young women.

\section{Methods and Subjects}

Fifty normal volunteers (25 men and 25 women) were studied. All were members of the hospital staff, and included medical Royal North Shore Hospital of Sydney, St. Leonards, N.S.W. 2065,
Australia

N. A. SAUNDERS, M.B., B.S., Medical Registrar

SANDRA HEILPERN, B.SC., Research Assistant

A. S. REBUCK, M.B., B.S., M.R.A.C.P., Honorary Physician; Lecturer in Medicine, University of Sydney officers, students, nurses, and lay staff. On the day of the rebreathing test each subject completed an Eysenck Personality Inventory (Eysenck and Eysenck, 1964), under the supervision of at least one of us. Each subject was given a standard explanation and instruction regarding the questionnaire. Subjects were excluded from the study if their cumulative lie score for forms $A$ and $B$ was equal to or exceeded 10 lies.

Each subject then rebreathed for four minutes from a 6-litre bag containing $7 \%$ carbon dioxide, $50 \%$ oxygen, and $43 \%$ nitrogen. The rebreathing bag was enclosed by an airtight Perspex container, which was connected to a spirometer (Pulmotest, Godart), allowing ventilation during rebreathing to be recorded. A continuous record of carbon dioxide percentage in the expired gas was obtained by drawing a sample of gas from the mouthpiece through an infrared carbon dioxide analyser (Capnograph, Godart) and back into the rebreathing bag.

Minute ventilation $\left(\dot{\mathbf{V}}_{\mathbf{E}}\right)$ was calculated from the spirometer tracing for each half-minute of the rebreathing test, and was plotted against the corresponding carbon dioxide tension $\left(\mathrm{PCO}_{2}\right)$ in the expired gas. All gas volumes were corrected to B.T.P.S. (body temperature, pressure, and saturation) conditions. The slope of the response line $\left(\Delta \dot{V}_{\mathbf{E}} / \Delta \mathrm{PCO}_{2}\right)$ was calculated by the least squares regression method. The correlation coefficient between personality score and $\Delta \dot{V}_{\mathbf{E}} / \Delta \mathbf{P C O}$, was found for the line of least squares regression for men and women.

Subjects were excluded from the study if their forced expiratory volume in one second $\left(\mathrm{FEV}_{1}\right)$ was less than $80 \%$ of the predicted value (Goldman and Becklake, 1959) or if there was a history of recent drug ingestion. One of us interviewed each subject, and no history of respiratory or psychiatric disease was obtained from any subject included in the study.

\section{Results}

Personality Study.-The extraversion (E), neuroticism (N), and lie (L) scores found in this study are similar to those described by Eysenck and Eysenck (1964) and are shown in Table I. There was no significant difference between men and women for $E$ score $(P>0.1), N$ score $(P>0.5)$, and L score $(P>0.05)$, though there was a tendency for women to have a lower $\mathrm{E}$ score and a higher $\mathrm{N}$ score than men. Eysenck and Eysenck's (1964) finding that $E$ and $N$ scores, as measured by the Eysenck Personality Inventory, are independent was upheld in our sample. There was no significant correlation between $E$ and $N$ score for the total group ( $r=0.11)$, men $(r=0.05)$, or women $(r=0.14)$.

Ventilatory Study.-The slope of the line of ventilatory response to increasing carbon dioxide tensions $\left(\Delta \dot{\mathrm{V}}_{\mathrm{E}} / \Delta \mathrm{PCO}_{2}\right)$ was calculated for each subject. A summary of these data is

TABLE I-Comparison of Extraversion, Neuroticism, and Lie Scores

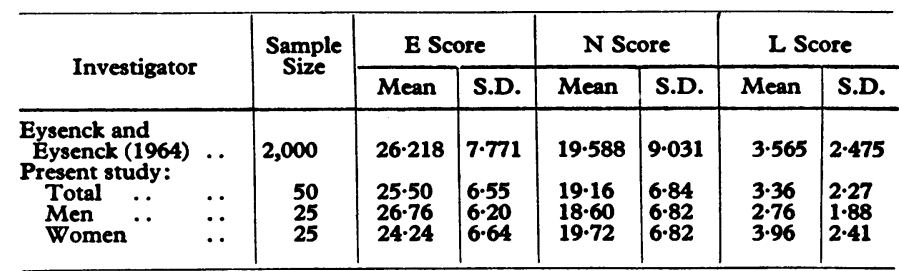


shown in Table II. The average slope of response for the women was significantly lower than the average slope for the men ( $P<0.025$, Student's $t$ test) though the range of responsiveness was similar in both groups.

Relation of Personality and Ventilatory Response.-The relations between personality and ventilatory response to carbon dioxide are shown in Table III. A significant correlation was found between extraversion score and $\Delta \dot{\mathrm{V}}_{\mathrm{E}} / \Delta \mathrm{PCO}_{2}$ in the total population $(P<0.05)$. When considered separately, however, the sexes formed two distinct groups in regard to $\Delta \dot{\mathrm{V}}_{\mathrm{E}} / \Delta \mathrm{PCO}_{2}$ and $E$ score. A highly significant correlation $(P<0.005)$ was found between slope of ventilatory response and extraversion in women (Fig. 1), whereas a random scatter $(P>0.9)$ was found in the men. There was no significant correlation between $\Delta \dot{\mathrm{V}}_{\mathrm{E}} / \Delta \mathrm{PCO}_{2}$ and neuroticism score in either men or women.

TABLE II-Ventilatory Response to Carbon Dioxide in 50 Normal Subjects

\begin{tabular}{|c|c|c|c|c|c|c|}
\hline & & & & \multicolumn{2}{|c|}{$\left(\Delta \dot{\mathrm{V}}_{\mathrm{B}} / \mathrm{\Delta \textrm {PCO } _ { 2 } )}\right.$} & \multirow{2}{*}{$\begin{array}{c}(1 . / \mathrm{min} / \mathrm{mm} \mathrm{Hg}) \\
\text { Range }\end{array}$} \\
\hline & & & & Mean & S.D. & \\
\hline $\begin{array}{l}\text { Men ... } \\
\text { Women }\end{array}$ & 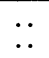 & $\ldots$ & $\because$. & $\begin{array}{l}2.43 \\
1.92\end{array}$ & $\begin{array}{l}0.85 \\
0.64\end{array}$ & $\begin{array}{l}0.75-3.85 \\
0.90-3.57\end{array}$ \\
\hline
\end{tabular}

TABLE III-Correlation Coefficients Between Slope of Ventilatory Response to Carbon Dioxide and Personality Score

\begin{tabular}{|c|c|c|c|c|c|}
\hline & & \multirow{2}{*}{\multicolumn{2}{|c|}{ No. }} & \multicolumn{2}{|c|}{$\left.\left(\Delta \dot{\mathrm{V}}_{\mathrm{V}} / \mathrm{APCO}\right)_{2}\right)$} \\
\hline & & & & E Score & N Score \\
\hline $\begin{array}{l}\text { Total. . } \\
\text { Women } \\
\text { Men }\end{array}$ & $\begin{array}{l}\cdots \\
\cdots \\
\cdots\end{array}$ & $\begin{array}{l}\cdots \\
\cdots \\
\cdots\end{array}$ & $\left.\begin{array}{l}50 \\
25 \\
25\end{array}\right\}$ & $\begin{array}{l}\mathbf{r}=0.29 \pm 0.13 \\
\mathbf{P}<0.05 \\
\mathbf{r}=0.61 \pm 0.13 \\
\mathbf{P}<0.005 \pm 0.20 \\
\mathbf{r}=0.01 \pm 0.20 \\
\text { N.S. }\end{array}$ & $\begin{array}{l}\mathbf{r}=-0.17 \pm 0.14 \\
\mathbf{N} . S . \\
\text { r. }-0.01 \pm 0.20 \\
\text { N.S. } \\
\text { r.s. }-0.12 \pm 0.20 \\
\text { N.S. }\end{array}$ \\
\hline
\end{tabular}

$r=$ Correlation coefficient \pm standard error. N.S. = Not significant.

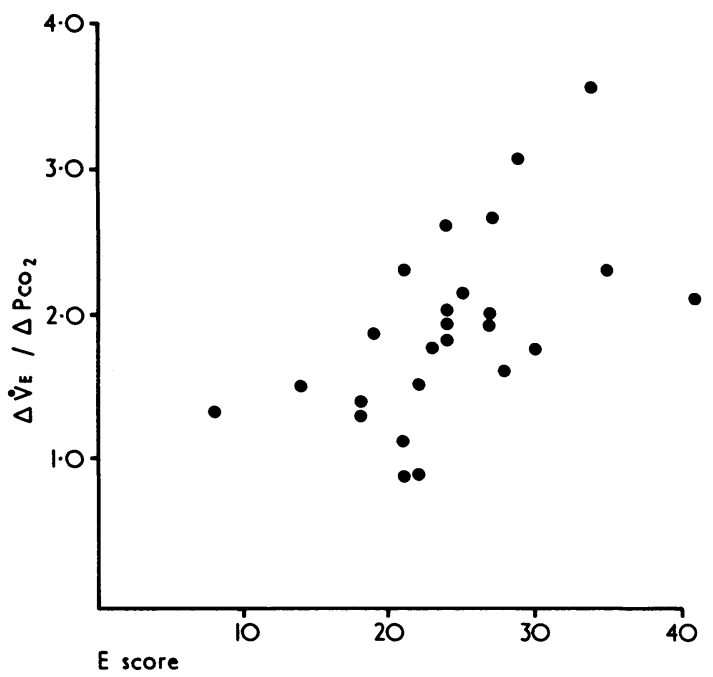

FIG. 1-Relation between extraversion score and slope of ventilatory response to carbon dioxide in women $\left(P<0^{\circ} 005\right)$.

\section{Discussion}

This study has shown a relation between personality structure and the sensitivity of the central respiratory chemoreceptors. Among the subjects studied a significant correlation was found between extraversion and slope of ventilatory response to carbon dioxide in healthy young women.
It seemed that the men and women were similar in regard to personality, for there was no significant difference in $E$ score $(P>0.1)$ or $\mathrm{N}$ score $(P>0.5)$ between the sexes. There was, however, a tendency for women to have a lower $\mathrm{E}$ score and a higher $\mathrm{N}$ score than men. This tendency has been noted previously (Eysenck and Eysenck, 1964). The average $E$ and $N$ scores for the total sample were similar to those described by Eysenck and Eysenck (1964), so the sample may be representative of the general population in this regard, even though they were motivated toward the study and were not randomly selected.

The average slope of response $\left(\Delta \dot{\mathrm{V}}_{\mathrm{E}} / \Delta \mathrm{PCO}_{2}\right)$ of the women we studied $(1.921 . / \mathrm{min} / \mathrm{mm} \mathrm{Hg})$ was significantly lower $(P<0.025)$ than the average slope of response in the $\operatorname{men}(2.431 . / \mathrm{min} / \mathrm{mm}$ $\mathrm{Hg}$ ), though the range of response was similar in both sexes. These findings are supported by a previous study of ventilatory response to carbon dioxide in healthy young women (Haywood and Bloete, 1969).

The present study has shown a significant correlation between $\mathrm{E}$ score and $\Delta \dot{\mathrm{V}}_{\mathrm{E}} / \Delta \mathrm{PCO}_{2}$ in women, such that those with the greater $\mathrm{E}$ score had the greater ventilatory response to carbon dioxide $(P<0.005)$. No significant correlation was found between $\mathrm{E}$ score and $\Delta \dot{\mathrm{V}}_{\mathrm{E}} / \Delta \mathrm{PCO}_{2}$ in men. The correlation (or lack of it) between $\mathrm{E}$ score and slope of response within the male and female groups is independent of any statistical relation between the sexes. Therefore the lack of correlation seen in the male group is not explained by the difference in slope of ventilatory response observed between the sexes. There was no significant correlation found between $\mathrm{N}$ score and $\Delta \dot{\mathrm{V}}_{\mathrm{E}} / \Delta \mathrm{PCO}_{2}$ in either sex.

Others have used the Eysenck Personality Inventory to test the clinical impression that personality was related to pulmonary ventilation and blood gas tensions in patients with chronic airways obstruction (Clark and Cochrane, 1970). These workers used a formula to predict mixed venous carbon dioxide tension $\left(\mathrm{P}_{\overline{\mathrm{v}}} \mathrm{CO}_{2}\right)$ from $\mathrm{FEV}_{1}$ (Burrows et al., 1965) and showed that patients with a lower than predicted $\mathrm{P}_{\bar{v}} \mathrm{CO}_{2}$ scored higher on the extraversion scale than did patients with a $\mathrm{P}_{\bar{y}} \mathrm{CO}_{2}$ higher than predicted. They noted that Eysenck (1960) had postulated a close relation between extraversion score and the degree of excitability prevalent in the central nervous system, and suggested that the correlation of extraversion score with $\mathrm{P}_{\overline{\mathrm{V}}} \mathrm{CO}_{2}$ might be due to increased central chemoreceptor excitability in extraverted patients. Clark and Cochrane (1970) could find no relation between neuroticism score and $\mathrm{P}_{\overline{\mathrm{v}}} \mathrm{CO}_{2}$ in their patients.

The finding that slope of ventilatory response was significantly related to $E$ score $(P<0.05)$, but not to $N$ score, in the total number of men and women we studied would seem to support the findings of Clark and Cochrane (1970). However, as the results reported here show a clear difference between the sexes in the relation of $\mathrm{E}$ score and $\Delta \dot{\mathrm{V}}_{\mathrm{E}} / \Delta \mathrm{PCO}_{2}$, it does not seem valid to discuss results in terms of the total population. The sex difference observed in this study was not reported by Clark and Cochrane (1970), so that it is not possible to compare our findings with their data in this regard.

While the present study has shown a difference between the sexes in the relation of extraversion score and $\Delta \dot{\mathbf{V}}_{\mathbf{E}} / \Delta \mathrm{PCO}_{2}$, it has not discovered the reason(s) for this difference. It may be that the relation between personality and slope of response is unique to women. However, it seems more likely that there is a multifactorial relation between ventilatory response and cortical function in both sexes and that one of these factors, extraversion, correlates significantly in women but not in men. No valid multifactorial analysis can be performed on the small numbers we have reported.

A comprehensive review of the psychological variables in asthma (Freeman et al., 1964) has shown that a large proportion of asthmatic patients have psychological disturbances, though no specific personality trait has been causally related to asthma. There is a high incidence of intraversion and neurotic behaviour in asthmatics, but whether this is a primary or secondary 
phenomenon is still not clear. It has recently been shown that ventilatory response to carbon dioxide in asthmatic patients, measured during recovery from attacks of asthma, plays some part in determining the level of carbon dioxide tension developed during attacks (Rebuck and Read, 1971). As a personality factor has now been shown to correlate with ventilatory response to carbon dioxide in women, it seems likely that, irrespective of the role of personality in the aetiology, precipitation, and continuation of asthmatic attacks, the degree of extraversion in any given asthmatic woman may play a part in the way in which pulmonary ventilation, and hence arterial carbon dioxide levels, are controlled in the presence of airways obstruction.

This work was supported by a donation to the Royal North Shore Hospital of Sydney for respiratory research. We would like to thank Mrs. Elizabeth Saunders for her technical help.
Requests for reprints should be sent to Dr. N. A. Saunders, Thoracic Unit, Royal North Shore Hospital of Sydney, St. Leonards, N.S.W. 2065, Australia.

\section{References}

Burrows, B., Strauss, R. H., and Niden, A. H. (1965). American Review of

Respiratory Diseases, $91,861$.
Clark, T. J. H. (1968). Clinical Science, 34, 559.

Clark, T. J. H., and Cochrane, G. M. (1970). British Medical fournal, 1, 273.

Eysenck, H. J. (1960). The Structure of Human Personality, 2nd edn. London, Methuen.

Eysenck, H. J., and Eysenck, S. B. G. (1964). Manual of the Eysenck Personality Inventory, London, University of London Press.

Freeman, E. H., Feingold, B. F., Schlesinger, K., and Gorman, F. J. (1964) Psychosomatic Medicine, 26, 543.

Goldman, H. I., and Becklake, M. R. (1959). American Review of Tuberculosis and Pulmonary Diseases, 79, 457.

Haywood, C., and Bloete, M. E. (1969). Fournal of Applied Physiology, 27, 32

Read, D. J. C. (1967). Australasian Annals of Medicine, 16, 20.

Rebuck, A. S., and Read, J. (1971). Clinical Science, 41, 13.

\title{
Management of Third Stage of Labour, with Particular Reference to Reduction of Feto-Maternal Transfusion
}

\author{
O. A. LADIPO
}

British Medical fournal, 1972, 1, 721-723

\section{Summary \\ Methods of management of the third stage of labour were compared in $\mathbf{2 0 0}$ cases, noting the effect on feto-maternal transfusion. The incidence of feto-maternal transfusion was found to be $66 \%$ in cases managed in the orthodox manner, compared with $33 \%$ in those in whom free cord bleeding was allowed. The magnitude of transplacental bleeding was also less when bleeding was allowed.}

\section{Introduction}

Feto-maternal transfusion occurs in varying degrees in all pregnancies. However, the rhesus-negative mother carrying a rhesus-positive baby is likely to be affected as a consequence of such a transfusion. Feto-maternal transfusion can occur in the antepartum and intrapartum period, but is much more likely in the latter period (Zipursky et al., 1959; Fraser and Raper, 1962; Sullivan and Jennings, 1966; Woodrow and Finn, 1966). The magnitude of such transfusion varies considerably, and in some cases the quantity is small with no apparent antigenic stimulus, while larger quantities may provoke rhesus-antibody formation.

Little stress has been laid on the management of the third stage of labour with reference to the reduction of transplacental haemorrhage, despite the fact that most of these transfusions occur at this stage. Dunn (1966) and Dunn and Fraser (1966) showed that early cord ligation and the use of oxytocic drugs increase the blood pressure within the placental vasculature during the third stage of labour. He suggested the possibility of increased transplacental transfusion as a result of the rupture of the large placental vessels and enlarged capillaries of the placental villi due to raised intravascular cord pressure.

It was of considerable interest when Terry (1970) showed that by allowing free cord bleeding in the third stage the volume and

\section{Royal Gwent Hospital, Newport, Monmouthshire}

O. A. LADIPO, M.B., CH.B., M.R.C.o.G., Senior House Officer (Present address: Department of Obstetrics, St. David's Hospital, Cardiff) pressure of fetal blood within the placenta may be reduced, with consequent diminution in the volume of feto-maternal transfusion. Free cord bleeding from the placental side was performed immediately the baby was born. However, evidence at present suggests that this method of draining the cord immediately at birth probably leads to a marked reduction in the placental transfusion of the baby (Gunther, 1957; Uscher et al., 1963), which may lead to an increased incidence of respiratory distress syndrome in small babies (Duckman et al., 1953; Bound et al., 1956, 1962; Moss et al., 1963, 1964).

An attempt has been made to compare the effects of three methods of managing the umbilical cord in the third stage on feto-macernal transfusion and on placental transfusion of the baby.

\section{Subjects and Method}

In this investigation only primigravida and gravida-2 rhesusnegative mothers who had an uncomplicated pregnancy, a spontaneous labour, and an unassisted vaginal vertex delivery were studied. Syntometrine, containing $0.5 \mathrm{mg}$ of ergometrine and 5 units of oxytocin, was injected intramuscularly at the time of delivery of the anterior shoulder. The placenta was delivered by Brandt Andrew's method. Thirty minutes after delivery $5 \mathrm{ml}$ of maternal blood was taken and put into a Sequestrene bottle. This was examined for fetal cells by the acid-elution technique of Kleihaur et al. (1957).

The third stage of labour was managed in one of three ways:

Method 1.-One hundred cases were managed in the orthodox manner of clamping the cord, and the placenta was delivered by Brandt Andrew's method.

Method 2.-In 62 cases the cord was clamped $12 \mathrm{~cm}$ from the navel as soon as the baby was born, a single artery forceps being used. This was followed immediately by division of the cord and free drainage from the placental side into a kidney dish. This volume of blood was measured (preplacental transfusion method).

Method 3.-In 38 cases late clamping of the cord was practised. The cord was clamped about $12 \mathrm{~cm}$ from the navel with a single artery forceps only after the cord pulsation ceased. The cord was then divided and free drainage from the placental side into a kilney dish was practised. The blood volume drained was measured (postplacental transfusion method). 